\title{
Control and Optimization of the Smart Grid by using Particle Swarm Optimization (PSO): To Reduce the Distribution Losses
}

\author{
Tibbie Pon Symon.V.A ${ }^{\# 1}$, Dr.I.Jacob Ragland ${ }^{* 2}$ \\ ${ }^{\#}$ Department of Electrical and Electronics Engineering, Noorul Islam University, Tamilnadu, India. \\ 1tibbiesymon@gmail.com \\ *Department of Electrical and Electronics Engineering, VIT, Vellore, Tamilnadu, India. \\ 2jacobragland@rediffmail.com
}

\begin{abstract}
In power systems, a demand side management with improved quality has an important role. The enhanced energy reduction and system control are necessary in the smart grid infrastructure. In this paper, the grids are arranged in such a way that the losses in it are reduced. The whole system is rearranged ie., the load connected to the grid is rearranged according to their use. The hospitals need twenty four hour power supply and the schools and colleges need only day time power supply. Lot of optimization techniques are used to find the stability of the system. A new and stochastic scheduling technique has to be used to handle the uncertainties in the system. The used techniques must be highly acceptable and it must handle the problems in the smart grid which we have taken into consideration. The Particle Swarm Optimization is used here which gives a good iteration result. The simulation results show that the proposed system gives the accurate results and the efficiency is also improved.
\end{abstract}

KeyWord - Demand side management, Home area network (HAN), Deregulated power system, smart grid, (PSO), wide area network (WAN).

\section{INTRODUCTION}

The complexity of the electrical grid and electric power system infrastructure is growing with the increase of load demands [4]. In many countries, the utility grids are source defined centralized power distribution systems [1]. The main problem faced by the power system is the loss in the distribution system because the load is not same. Some of the load may be inductive, some are capacitive and some are purely resistive and the combination is also be there. Some applications may take high power and some may take low power. Faults in the equipments may also cause power loss. The loss is mainly due to the improper arrangement in the infrastructure of the distribution side. The power taken by the consumer is usually more in the peak time and some of the grids may take more than the rated value. The main reason is that the various needs of the consumers. The consumer habit is also one of the reasons for the power loss. But more importantly, the demand management reduces or may be eliminated the need for activating supplementary power generation source so as to satisfy high demand at peak times [2].

The normal meaning of alleviate peak loads is moving non-emergency power demands at off peak load times. The total demand is satisfied by maintaining some critical value or threshold value, hence the reliability of the grid is increased. If the reliability of the grid is increased then the reliability of the entire system is increased. If we proved the supplementary power for the high power consuming consumers, it is costly for the operators to provide the average base power for consumed load. Additional maintenance and care is needed when the power supply is additionally added. This will again leads to the power loss and money loss. The main thing is the additional power suppliers or generating plants are occasionally turned on, it may be expensive to generate ( Eg: from gas or micro turbines) or it is to be imported from other countries at very high cost. Hence, the demand side load management reduces the cost of the operating grid while from the user aspect it lower real time electricity prices [2].

The smart grid allows the consumers to smartly consume electricity both by selecting the preferred suppliers and scheduling the operations of each appliance according to the various conditions including the price change and current load. Now demand side management[3] is becoming more important to meet the consumer requirements as well as to achieve the system goals such as peak load reduction, power saving, energy efficient, time saving, low cost etc..[8]. Now a days the load increasing in a spontaneous manner. Even the vehicles are also changing and changed to electrically operated. Trains are also changed to electric trains. Plug in hybrid electric vehicles (PHEV) are also coming to the market. This consideration can possibly lead to a serious problem, such as power provision and temporal power shortage.

Changing consumer habits involves awareness-raising programs which are often undertaken by government or activist groups. Simple things to be done are turning off lights in unoccupied rooms or switching off the television at night and setting tasks such as laundry for non-peak hours are few examples among the 
possibilities. New technologies will be added in the power grid for meeting the demands in future. In the power stations the latest and more flexible grid management methods will meet the increasing proportion of the renewable energy sources with conventional infrastructures associated.

Reducing the resource consumption is one of the important parameters. Day by day, the natural resources are reducing but the renewable energy is still available and that should be used in an efficient manner. Many countries are now using the renewable energy resources like wind and solar energy more efficiently. The major disadvantage of this renewable energy is that the wind will not be there for long time and the sun will not shine for the whole day. Most of the developed countries depend on this noise and pollution free renewable energy resources.

Another two things are delivering electrical energy more efficiently and changing the consumer habits. It is one of the major facts which is taken under consideration. In some cases efficient delivery will not be possible due to the complex network. But this can be achieved by using more advanced devices and technologies. Another way is by scheduling the power among the grids as well as the distribution system. Power scheduling will become very much disturbance for the consumers. In this work, a more efficient technology is used instead of power scheduling[5]. Power scheduling may be more in consumer side, but if there is no other way we have to choose it as a method because the demand is increasing now a days but the generation is not much increased.

The generation and distribution system is challenged due the dynamic increase in the energy demand and the spontaneous rise in the global emission of green home gases. The grid is a complex operator consisting of large input like solar, thermal, wind etc... connected together and the large and various types of loads connected to it. So in the proposed PSO system we have considered the solar power and the wind generated power. In consumer case, we consider that the consumer consumes his maximum capacity. Furthermore, in this proposed PSO[6] based proposed system of energy consumption, the scheduling solution result within ten seconds which is fast enough for the smart grid to schedule the power [7].

Micro generation model is the combination of various sources such as wind turbines, fuel cells and solar cells [9]. This combination of the different sources together leads to a new design of Hybrid Renewable Energy System (HRES) [10]. It reduces the fuel consumption and it reduces the cost also. For better efficiency and endurance of HRES proper energy and load management is needed [11]. The architecture of the HRES system is given in Fig.1.

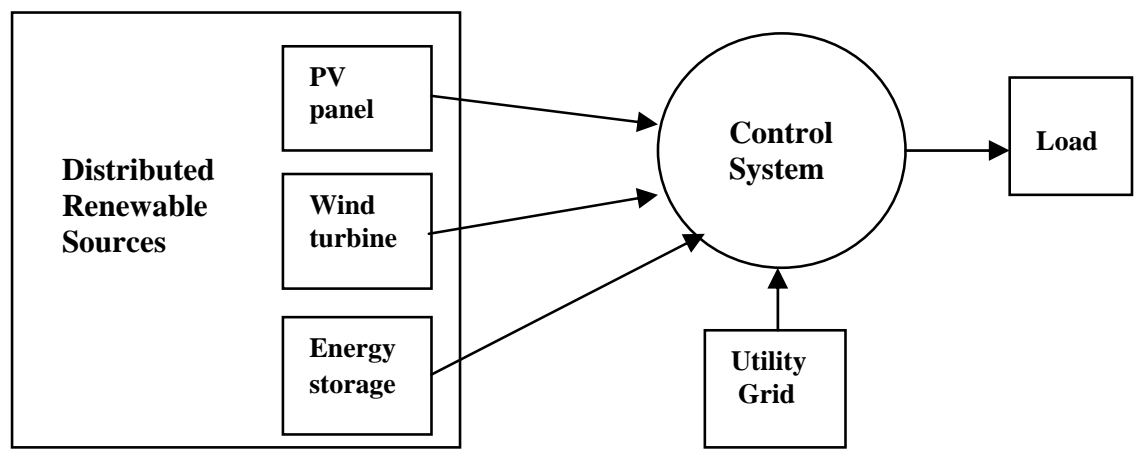

Fig.1. Architecture of HRES

In this HRES, a battery is used to meet either the peak demand or non availability of renewable sources of energy [10]. The intermittency of the renewable energy results to unpredictable fluctuations, which appears in the power output [12]. These problems can be solved by including some of the storage mechanisms such as batteries, compressed air, water pumping, fly wheels and ultra-capacitors [13]. The energy taken from the various generations, renewable sources, can be either utilized for powering the load or to recharge the battery. Therefore a balanced optimization technique is needed to meet the balance between the consumption of energy from renewable energy sources and recharging the battery source. The smart grid is a developing area and lot of research and experiments can be done in the paper design and also in the laboratories [14].

\section{SIMULATION TOOL}

The proposed simulation tool is designed on the basis of the demand side management (DSM). It will shift demand from peak to off-peak periods or shrink the electricity peak demand [15]. The architecture of the proposed tool is shown in Fig.2. In this the tool simulates the operation of a smart home. The smart home consists of a wide area network (WAN) which is connected to a communication network. the communication network can be either an internet or any other communication sources. The most commonly used one is the internet. The used tool will monitor all the consumers as well as appliances connected in the houses. 


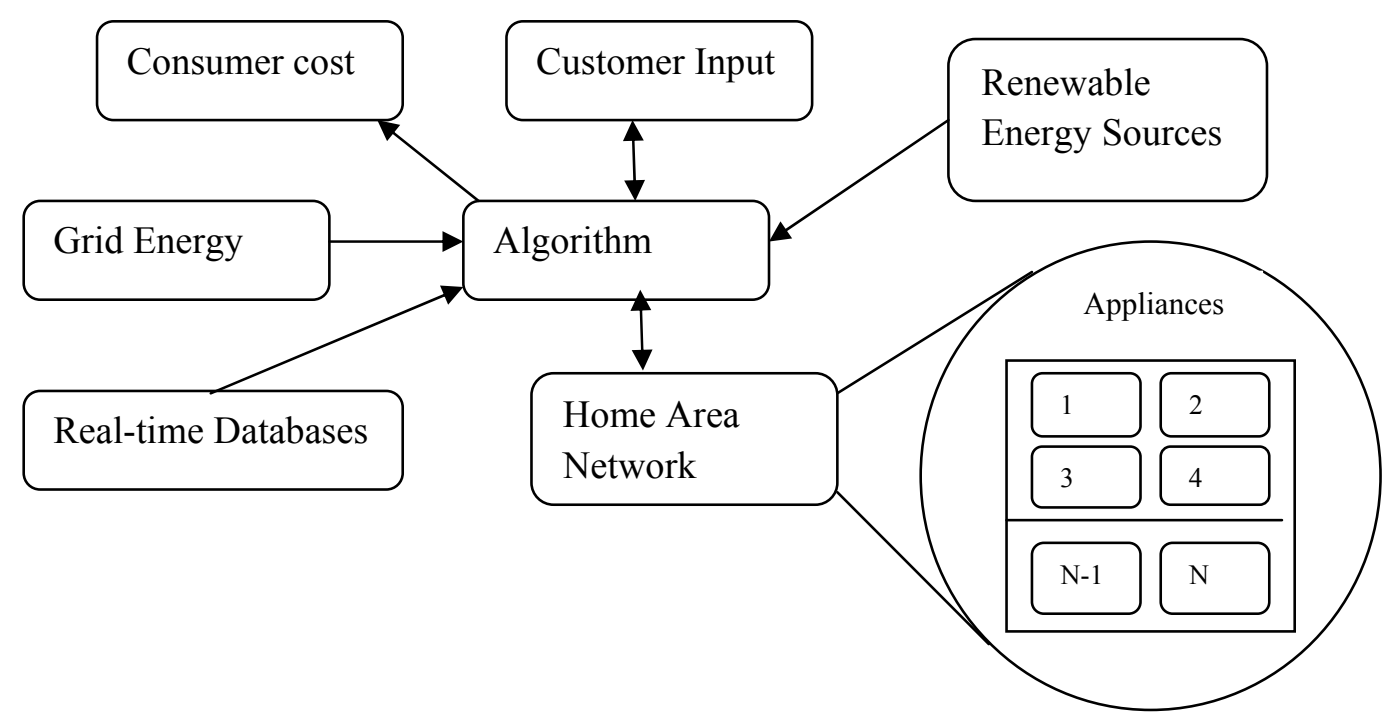

Fig. 2: The architecture of the proposed tool

If any one of the appliances is on fault it will also be monitored and informed to the consumers. Also it will monitor the power consumed by the consumers. Each Home Area Network (HAN) is defined by a set of user defined or pre determined appliances connected to a central processing or metering device. Based on the algorithm of the tool it simulates the functioning of the central processing unit [15].

\section{PROBLEM SOLVING}

The problem solving in the proposed system is done with the help of the following equations.

A. Design

Consider a function $\mathrm{F}(\mathrm{x})$, where

$$
\mathrm{F}(\mathrm{x})=(\mathrm{E}-((1-\mathrm{i}) *(\mathrm{PV}+\mathrm{WE}))) * \mathrm{CR}
$$

$\mathrm{i}$ is the optimization parameter

$\mathrm{E}=$ appliances total energy consumption

$\mathrm{CR}=$ cost rate

$\mathrm{PV}=$ solar energy

$\mathrm{WE}=$ wind energy

The amount of energy to charge the battery at any instant is given in the following equation

$$
\mathrm{i}^{*}(\mathrm{PV}+\mathrm{WE})
$$

The difference between maximum capacity of the battery and the amount available for the given instant during the recharge

$$
\mathrm{G}(\mathrm{x})=\mathrm{E}_{\mathrm{b}}-\left(\mathrm{E}_{\mathrm{ba}}+\mathrm{i} *(\mathrm{PV}+\mathrm{WE})\right)
$$

$\mathrm{E}_{\mathrm{b}}=$ the maximum battery capacity

$\mathrm{E}_{\mathrm{ba}}=$ the maximum energy available at the time of calculation

At any instance, the value of $x$ is a percentage value and it is in $0 \leq i \leq 1$

During the recharging $\mathrm{G}(\mathrm{x}) \geq 0$

$$
\text { i.e } \quad \mathrm{E}_{\mathrm{b}}-\left(\mathrm{E}_{\mathrm{ba}}+\mathrm{i} *(\mathrm{PV}+\mathrm{WE})\right) \geq 0
$$

\section{B. Particle Swarm Optimization (PSO)}

Particle Swarm Optimization (PSO) is applied widely in the area for problem solving. This PSO algorithm is based on the activities of a group of animals which does not have any organizer in their group [16]. Here, the group of animals will not have any leader and they will randomly find out their food by following a member of their group with the nearby location from the food. This is a type of potential solution for the problem. The members of the group attain the best condition concurrently by making the communication between the group members who already have a better condition. These members will intimate it to the group then they will also go to that place. This process will be repeated until the best solution or a food source is found out. 
The PSO algorithm [17] to find out the best possible value follows the behavior of the animal societies. It contains a group of particles and each particle represents the potential solution [16]. Kennedy and Eerhart are the persons who developed the concept of PSO in 1995. It was the novel heuristic technique and motivated by some public activities which was demonstrated by a group of birds or animals. This will be used to discover certain parameters that are necessary to achieve the desired objectives.

As defined above the PSO algorithm will optimize throughout the system and it will find out the real and most suitable value in this. In the binary particle swarm optimization (BPSO), the particle's personal best and global best position is reorganized as in real valuated version.

\section{Simulation results}

For obtaining better simulation results we have to consider how much of energy is produced in each hour of a day for wind as well as in solar plant. MATLAB is used for the simulation. They are shown in the below tables. Table I is for wind energy and Table II is for solar energy.

TABLE I. Wind Energy from wind farm

\begin{tabular}{|l|l|l|l|l|l|l|l|l|}
\hline Hour of Duty in a day & $\mathbf{1}$ & $\mathbf{2}$ & $\mathbf{3}$ & $\mathbf{4}$ & $\mathbf{5}$ & $\mathbf{6}$ & $\mathbf{7}$ & $\mathbf{8}$ \\
\hline Insolation (W/m2) & 45.1 & 16.7 & 5.7 & 34.6 & 20.8 & 27.2 & 36.8 & 12.2 \\
\hline Hour of Duty in a day & 9 & 10 & 11 & 12 & 13 & 14 & 15 & 16 \\
\hline Insolation (W/m2) & 6.5 & 37.6 & 3.0 & 31.6 & 19.7 & 44.2 & 11.3 & 11.4 \\
\hline Hour of Duty in a day & 17 & 18 & 19 & 20 & 21 & 22 & 23 & 24 \\
\hline Insolation (W/m2) & 13.7 & 27.6 & 34.9 & 20.9 & 31.1 & 3.24 & 35.1 & 2.0 \\
\hline
\end{tabular}

TABLE II. Solar energy from solar plant

\begin{tabular}{|l|l|l|l|l|l|l|l|l|}
\hline Hour of Duty in a day & $\mathbf{1}$ & $\mathbf{2}$ & $\mathbf{3}$ & $\mathbf{4}$ & $\mathbf{5}$ & $\mathbf{6}$ & $\mathbf{7}$ & $\mathbf{8}$ \\
\hline Insolation (W/m2) & 0 & 0 & 0 & 0 & 0 & 0 & 57 & 215 \\
\hline Hour of Duty in a day & 9 & 10 & 11 & 12 & 13 & 14 & 15 & 16 \\
\hline Insolation (W/m2) & 346 & 703 & 956 & 1045 & 988 & 948 & 898 & 788 \\
\hline Hour of Duty in a day & 17 & 18 & 19 & 20 & 21 & 22 & 23 & 24 \\
\hline Insolation (W/m2) & 580 & 351 & 76 & 0 & 0 & 0 & 0 & 0 \\
\hline
\end{tabular}

The PSO algorithm will go for a number of iterations and it will give out the best result. The values taken from the wind and the solar plants are entered into the PSO algorithm and it will calculate the better one from the function equation ie.. Equation (1). Where ' $i$ ' is the optimization parameter. After the iterations over the smart grid and the connected load the simulation result for the efficiency is given below. The efficiency input to the PSO is shown in Fig.3 and the efficiency output from the PSO is shown in Fig.4.

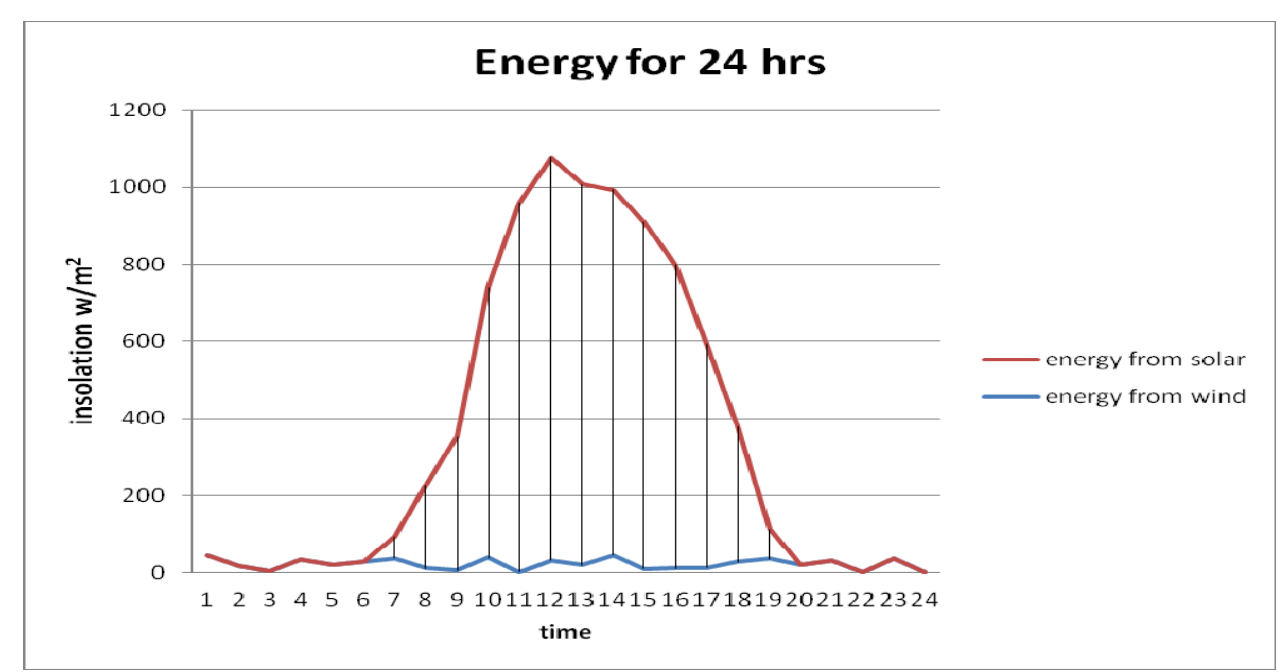

Fig. 3. Efficiency input to PSO 


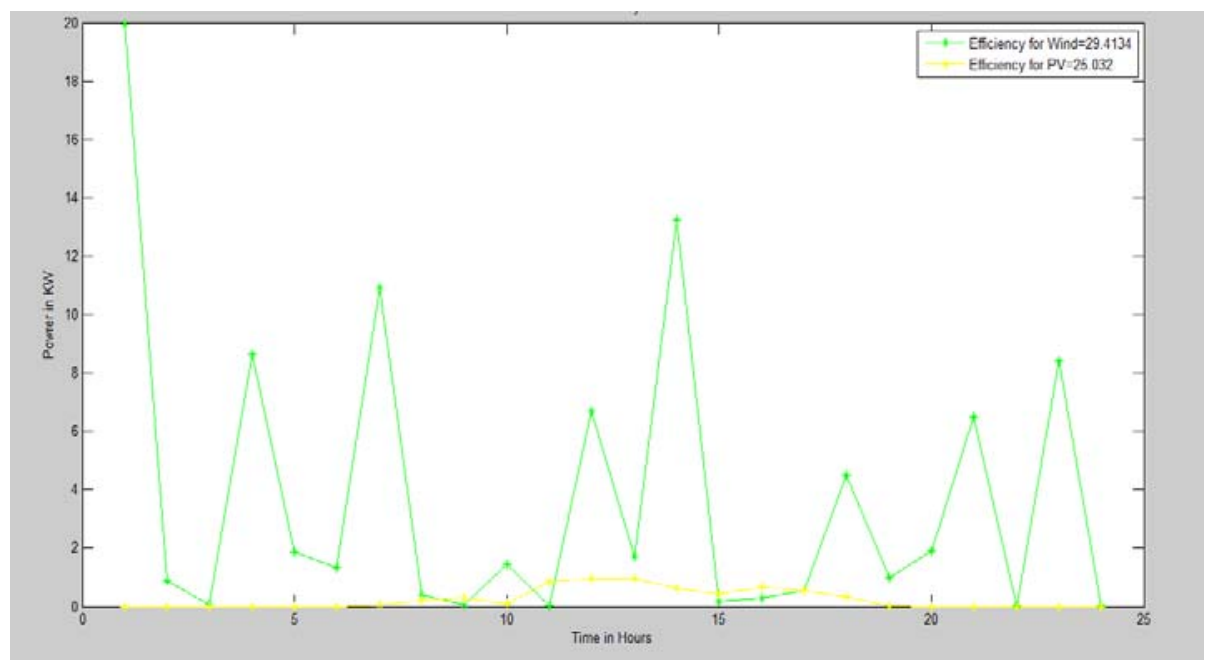

Fig: 4. Efficiency output by PSO from MATLAB

\section{CONCLUSION}

Particle swarm optimization (PSO)[18][19] used for the development and testing of the consumer based DSM is presented in this paper. The simulation results for the efficiency are also shown. By using this PSO the smart grid can be used in more efficient and more reliable way. Thus the power losses can be reduced and it can be developed in home structures. It gives an excellent performance in the system as well as possible benefits for DSM. The tool simulates a house hold environment. Also it provides the consumer a real time analysis of optimized appliance selection and resource management.

The result from the PSO simulation achieves an average of $28 \%$ of cost saving for the end-user. These results lead to significant annual savings for the customer. This PSO totally reshuffle the grid system by choosing the most efficient way and gives accurate result. It is used for extending the research and for the improvement of the power system as well as the grids. The new concept is developed for the future work. The results will be compared with the cuckoo search algorithm or within any algorithm like fire fly, bat, or ant colony. And the efficiency results will be compared and the better one will be selected for practice.

\section{REFERENCES}

[1] NIkil Gudi,Lingfeng Wang, Vijay Devahakunti, A demand side management based simulation platform incorporating heuristic optimization for management of household appliances, Electrical power and energy system, Science Direct, Vol. 43, 2012.

[2] Clastres C. Smart grids: "Another step towards competition, energy security and climate change objectives", Energy Policy, Vol.5, 2011, pp.399-408

[3] Di Zang,Nilay Shah, Lazarous G. Papageorgiou, "Efficinet energy consumption and operation management in a smart building with microgrid", Energy conservation and management, Vol. 74, 2013.

[4] US department of energy. The smart grid: An introduction, 2008.<http://www.oe.energy.gov/SmartGrid Introduction.htm.

[5] Armas J M, Suryanarayanan S, A heuristic technique for scheduling a customer driven residential distributed energy resource Installation, Proc. 15th int'l conference on intelligent systems applications to power systems; 2009. pp. 1-7.

[6] Dian Palupi Rini, Siti Mariyam Shamsuddin , Siti Sophiyati Yuhaniz, Particle Swarm Optimization: Technique, System and Challenges, International journal of computer application, Vol .4, 2011.

[7] Mojtaba Khanabadi, Hassan Ghasemi, and Meysam Doostizadeh, Optimal Transmission Switching Considering Voltage Security and N-1 Contingency Analysis, IEEE Transactions on Power Systems, Vol. 28, No. 1, February 2013.

[8] Dell R, Rand D, "Energy storage: a key technology for global energy sustainability", Journal of Power Source, 2001, Vol.100, No. 1, pp.2-17.

[9] Watson J, "Co-provision in sustainable energy systems: the case of microgeneration". Energy Policy 2004;32(17):1981-90.

[10] Deshmukh MK, Deshmukh SS. "Modeling of hybrid renewable energy systems". Renewable Sustain Energy Rev 2008;12(1):235-49.

[11] Hajizadeh A, Golkar MA. Intelligent power management strategy of hybrid distributed generation system. Electr Power Energy Syst 2007;29:7 p, 83-95.

[12] Anderson D, Leach M," Harvesting and redistributing renewable energy: on the role of gas and electricity grids to overcome intermittency through the generation and storage of hydrogen". Energy Policy 2004;32(17):1603-13.

[13] Dell R, Rand D. Energy storage: a key technology for global energy sustainability. J Power Source 2001;100(1):2-17.

[14] Nikhil Gudi, Lifeng Wang, A demand side management based simulation platform incorporating heuristic optimization for management of household appliances. Electrial power energy systems 43(2012) springer 185-193

[15] National solar radiation data base; 2010. <http://rredc.nrel.gov/solar/old_data/nsrdb/>.

[16] Valle YD, Vanayagamoorthy GK, Mohagheghi S, Hernandez JC, Harley RD, Particle swarm optimization: basic concepts, variants and applications in power systems, IEEE Transactions on Evol.Comput, 2008, Vol. 12, No.2, pp.171-195.

[17] Kennedy J, Eberhart R. "A discrete binary version of particle swarm optimization". In: IEEE conf on systems man and cybernetics, Orlando, FL, vol. 5; 1997. pp. 4104-08.

[18] Khanesar MA, Teshnehlab M, Shoorehdeli MA. "A novel binary particle swarm optimization”. In: Mediterranean conference on control and automation, Athens, Greece; 2007. p. 1-6.

[19] Wang L, Singh C. "Unit commitment considering generator outages through a mixed-integer particle swarm optimization algorithm". Application of Soft Computing 2009;9:947-53. 


\section{AUTHOR PROFILE}

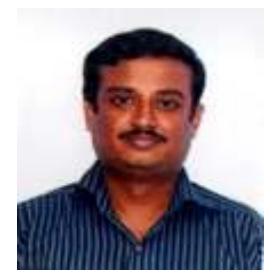

Tibbie Pon Symon.V.A received his Bachelors degree in Electrical and Electronics Engineering from Kannur University, Kerala, India in 2001 and the Masters degree in Power Electronics from Karunya University, India. Now he is doing $\mathrm{PhD}$ in Noorul Islam University, India and also working as an Assistant Professor in the department of Electrical and Electronics Engineering, Noorul Isalm University, Tamil Nadu, India. His area of interest is Power System and Power Electronics and the research area is in Loss Reduction in Power System.

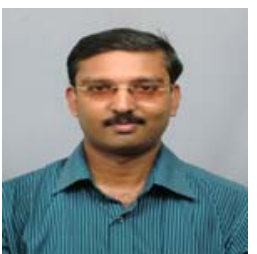

Dr. I. Jacob Raglend received his Bachelors degree in Electrical Engineering from The Indian Engineering College and the Masters degree in Power Systems Engineering from Annamalai University with first class in 2000 and 2001 respectively. He has done his Ph.D. degree in the Department of Electrical and Electronics Engineering, Indian Institute of Technology, Roorkee, India in the year 2007. Presently he is working as a Professor in the School of Electrical Engineering, Vellore Institute of Technology (VIT) India. He taught course in Basic Electrical Engineering, Power Systems, Artificial Intelligence and Soft Computing Techniques. His field of interest is Unit Commitment, Economic Dispatch, Smart Grid, Power System Restructuring and Deregulation, Artificial Intelligence Applications to Power System and FACTS. 